\title{
Endoscopic removal of metal bottle cap from the esophagus
}

A 22-year-old man was admitted to the emergency department with dysphagia and chest pain after inadvertently swallowing a metal bottle cap. Two hours earlier he had opened a bottle of cider using his teeth and accidently swallowed the bottle cap with the first sip of cider. After the incident, he was able to swallow fluids and saliva. He had no other previous medical history and no background of psychiatric illness. His vital signs were within normal limits. Physical examination revealed no abnormalities.

Thoracoabdominal radiograph showed a foreign body (the bottle cap) in the proximal part of the esophagus with no signs of perforation ( $>$ Fig. 1 ). With the assistance of an anesthesiologist, the patient underwent esophagogastroduodenoscopy and the bottle cap was seen in the esophagus ( $\mathbf{F i g . 2}$ ). The cap was difficult to retrieve because it was quite large and sharp. In order to avoid mucosal trauma, an endoscope with overtube (Guardus Overtube; US Endoscopy, Mentor, Ohio, USA) was inserted. The foreign body was then safely withdrawn under direct visualization using grasping for-

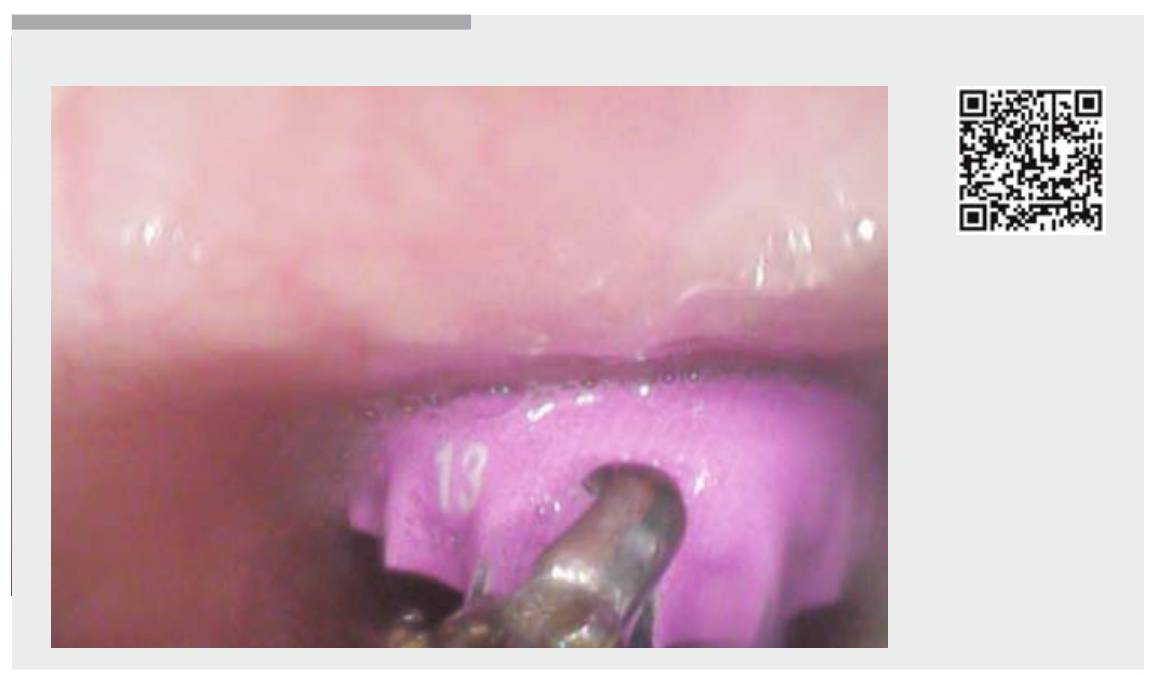

Video 1: Radiographic view and endoscopic removal of the metal bottle cap from the esophagus.

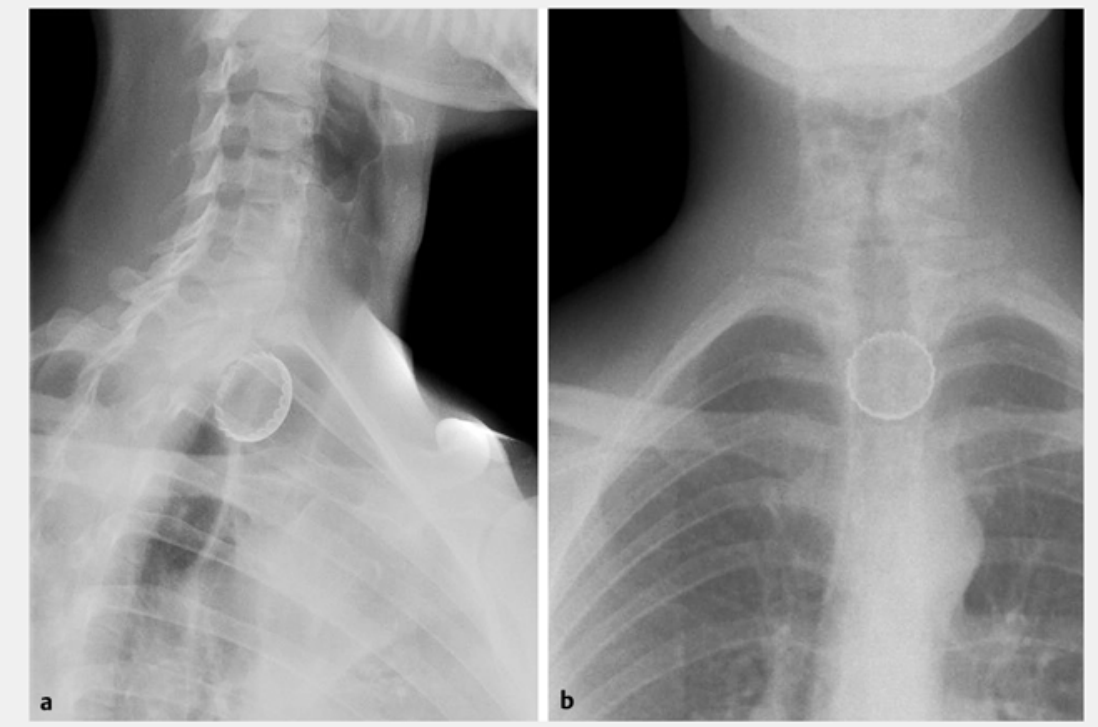

- Fig. 1 Radiograph showing foreign metallic body (bottle cap) in the proximal part of the esophagus. a Lateral view. b Posterior-anterior view. ceps (Rat tooth and alligator jaw grasping forceps; Olympus, Tokyo, Japan) ( $\triangleright$ Fig. 3, $>$ Video 1). After removal of the foreign body, the endoscope was re- introduced, and further examination revealed no sign of complications.

Foreign body ingestion and food bolus impaction are commonly encountered in clinical practice, especially in the pediatric population [1]. Approximately $10 \%$ $20 \%$ of these cases require endoscopic removal [1]. The European Society of Gastrointestinal Endoscopy guideline recommends the retrieval of sharp-pointed objects and batteries from the esophagus, and all foreign bodies inducing complete esophageal obstruction, within 2-6 hours [1]. Although the bottle cap did not completely block the esophagus, we categorized this specific foreign body as a sharp-edged object and therefore we performed emergency therapeutic gastroscopy.

Endoscopy_UCTN_Code_TTT_1AO_2AL

Competing interests

None 


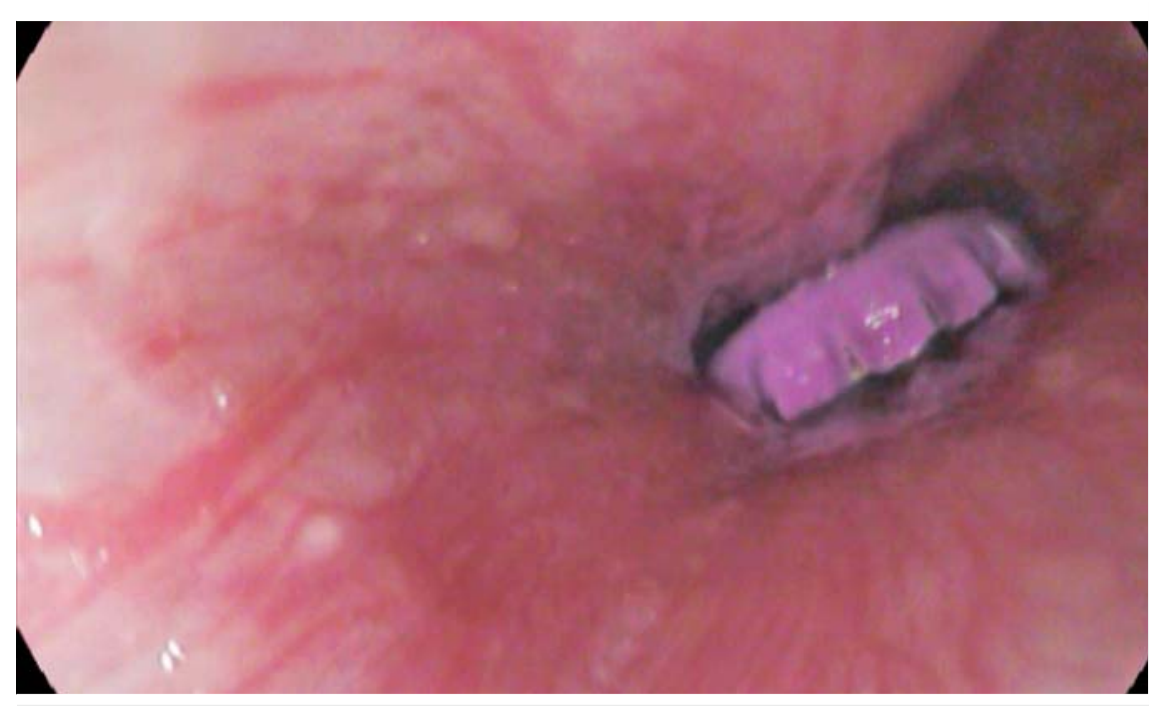

- Fig. 2 Endoscopic view showing foreign metallic body (bottle cap) in the esophagus.

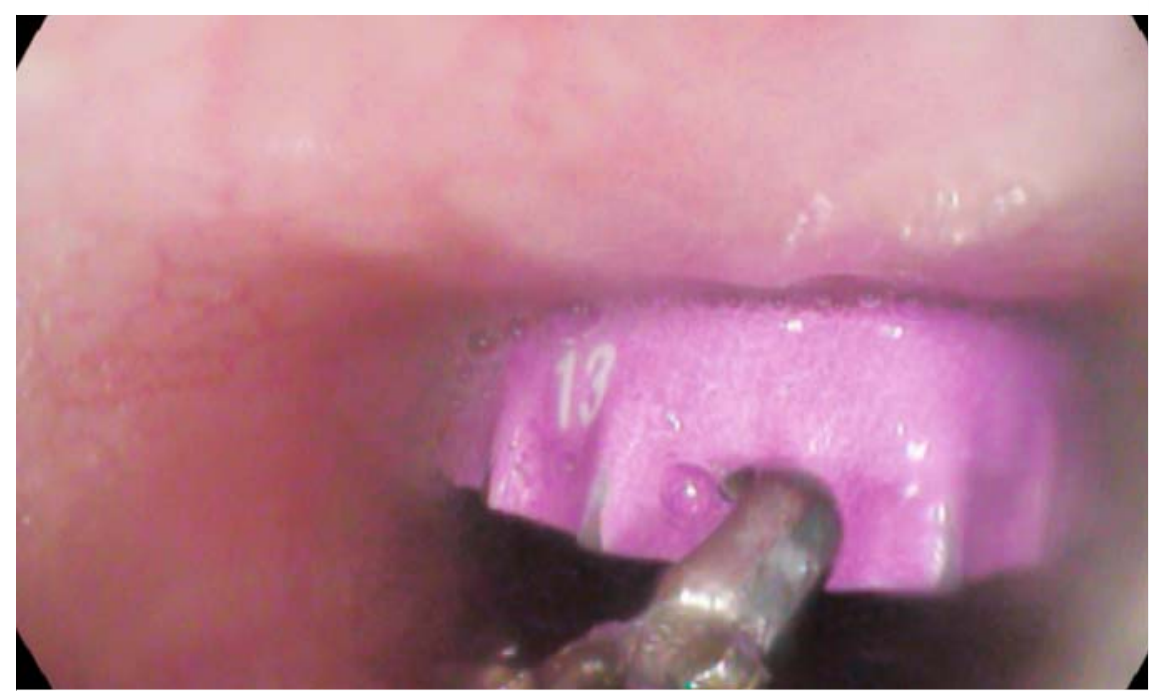

- Fig. 3 Endoscopic view showing the bottle cap being withdrawn under direct visualization using grasping forceps.
The Authors

Lukasz Rojek, Andrzej Jasinski, Krystian Adrych

Department of Gastroenterology and

Hepatology, Medical University of Gdańsk,

Gdańsk, Poland

\section{Corresponding author}

\section{Lukasz Rojek, MD, PhD}

Department of Gastroenterology and Hepatology, Medical University of Gdansk, Smoluchowskiego 17, 80-214 Gdańsk, Poland

Fax: +48-58-3493640

Irojek@gumed.edu.pl

\section{Reference}

[1] Birk M, Bauerfeind P, Deprez P et al. Removal of foreign bodies in the upper gastrointestinal tract in adults: European Society of Gastrointestinal Endoscopy (ESGE) Clinical Guideline. Endoscopy 2016; 48: 1-7

\section{Bibliography}

DOI https://doi.org/10.1055/s-0043-107026

Endoscopy 2017; 49: E163-E164

(c) Georg Thieme Verlag KG

Stuttgart · New York

ISSN 0013-726X

\section{ENDOSCOPY E-VIDEOS \\ https://eref.thieme.de/e-videos}

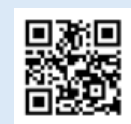

Endoscopy E-Videos is a free access online section, reporting on interesting cases and new techniques in gastroenterological endoscopy. All papers include a high quality video and all contributions are freely accessible online.

This section has its own submission website at

https://mc.manuscriptcentral.com/e-videos 